\title{
Unexpected hazard due to Fumonisins contaminating herbal teas used traditionally by Saudi people
}

\author{
Fardos M. Bokhari ${ }^{1}$ and Magda M. Aly ${ }^{* 1,2}$ \\ ${ }^{1}$ Biology Department, Faculty of Sciences, King Abdulaziz University, Saudi Arabia. \\ ${ }^{2}$ Botany Department, Faculty of Science, Kafr El-Sheikh University, Egypt.
}

Accepted 27 November, 2012

\begin{abstract}
Fumonisins are mycotoxins synthesized by various species of the genus Fusarium and are hazardous for human and animal health. The purpose of this study was to investigate fumonisin B1 (FB1) in herbal tea consumed especially by Saudi population. FB1 was detected using high performance liquid chromatography (HPLC) with fluorescence detection. Forty-seven commercially available samples for infusions preparations were collected and analyzed for FB1. The detectable amount for FB1 ranged from $0-266 \mu \mathrm{g} / \mathrm{kg}$. All the herbal tea samples were evaluated for the fungal contamination and the presence of mycotoxigenic fungi. Results indicate that predominant mycoflora were distributed in 13 genera representing 25 species. From these, the genera Aspergillus, Penicillium and Fusarium which considered extremely important from the mycotoxicological standpoint were the most abundant fungi. The presence of toxigenic moulds represents a potential risk of mycotoxin contamination. Considering the worldwide increased use of herbal products as alternative medicines, it is necessary setting standards for moulds in crude herbal tea in order to reduce the risks for consumers' health.
\end{abstract}

Key words: Fumonisins, herbal tea, mycotoxins, fungi, Fusarium, toxigenic fungi.

\section{INTRODUCTION}

The ubiquitous nature of fungal contamination has resulted in high levels of various mycotoxins in many food crops throughout the world (Aziz et al., 1998; Tutelyan, 2004). Such high levels of mycotoxins, especially aflatoxins, fumonisins $B$ or ochratoxin $A$, in food and feed commodities may have adverse effects on human and animal health, provoking different kinds of mycotoxicoses including carcinogenic effects (Tutelyan, 2004). According to Yang (1980) and Marasas et al. (1988), outbreaks of human oesophageal cancer were linked to the consumption of fumonisin-contaminated maize.

Fumonisins are mainly produced by Fusarium verticalioides and F. proliferatum, which are both field pathogens. Although at least 15 different fumonisins have been reported, structurally seven different well known fumonisins, FA1, FA2, FB1, FB2, FB3, FB4 and FC1, have been described (WHO, 2000). FB1 and FB2 are the most abun-

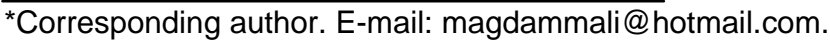

abundant in naturally contaminated food such as corn, medicinal plants and herbal tea and they are toxic to Turkey poultry, broiler chickens and may produce nephrotoxicity in rats (Omurtag et al., 2005). International Agency for Research on Cancer has declared $F$. moniliforme toxins as potentially carcinogenic to humans (class 2B carcinogens) and FB1 is a cancer promoter and play an important role in carcinogenesis in humans (Chu and Li, 1994; Yoshizawa et al., 1994).

Field fungal pathogens infect plants while they are growing in the field while post harvest pathogens grow and transit especially under inappropriate conditions of temperature and humidity (Hasan and Abdel-Sater, 1993; Bokhari and Aly, 2009). Indeed, warmer temperatures and higher humidity is most conducive to mold development during this post harvest period. Herbal tea including black, green or contain one or two ingredients like chamomile, lemon or ginger may be stored in adverse climatic conditions and are subjected to increased levels of fungal and mycotoxin contamination.

Authors detected fumonisin B1 and B2 in cereal, cereal 
products, medicinal plants and herbal tea (Atak and Omurtag, 2003; Omurtag et al., 2005). Moreover, fungal contaminated herbal tea samples were analyzed for a range of mycotoxins including ochratoxin $A$ and zearalenone as well as aflatoxins and Ochratoxin A was found in $15 \%$ of the analyzed samples. Medicinal plants and probably herbal teas especially if stored improperly, were susceptible to fungal growth and should therefore be routinely tested for the presence of fungi and mycotoxins before entering the market. FB1 was detected in 55 $(65.5 \%)$ of the 87 samples of herbal tea collected from Portugal and the highest number of positive samples was found in black tea (88.8\%) with levels ranging from 80 to $280 \mu \mathrm{g} / \mathrm{kg}$ (Omurtag and Yazıcıoglu, 2004).

With regard to human health, epidemiological studies established a positive correlation between the level of FB1 consummation in a diet and the rate of human esophageal cancer, liver damage and levels of certain classes of lipids, especially sphingolipids. In addition, maternal ingestion of high levels of FB1 during early pregnancy may increase the risk of neural tube defects of the brain and spinal cord (Gelineau-van Waes et al., 2005; Missmer et al., 2006). Studies on risk assessment of mycotoxins in herbs continue to rise throughout the world with respect to mycotoxins contamination of herbal tea. The main objective of this study was to determine the incidence and levels of mycotoxins in herbal tea in Jeddah, Saudi Arabia in addition to different contaminated fungi.

\section{MATERIALS AND METHODS}

\section{Collection of herbal tea samples}

A total of 47 samples belonging to 15 kinds of herbal tea were collected from supermarkets and street bazaars in Jeddah, Saudi Arabia. Each sample was collected in a sterile polyethylene bag, sealed, transferred immediately to the laboratory and kept in a cool place for fungal determination and mycotoxins analysis.

\section{Moisture content of the herbal tea samples}

The moisture content of the samples was directly determined by dry weight method (Aziz, 1987). About $10 \mathrm{~g}$ of each sample was transferred to an oven at $60^{\circ} \mathrm{C}$ under vacuum for $12-24 \mathrm{~h}$ until a constant weight and percentage of water content was calculated.

\section{Mycological analysis}

Ten grams of each sample were added to a $90 \mathrm{ml}$ of sterile saline solution in $250 \mathrm{ml}$ Erlenmeyer flasks and homogenized thoroughly on an electrical shaker at constant speed for $15 \mathrm{~min}$. Ten fold serial dilutions was then prepared (Bokhari and Aly, 2009) and one $\mathrm{ml}$ of the suitable dilution of the resulting medicinal plant suspension was used to inoculate Petri dishes, each containing $15 \mathrm{ml}$ of agar medium containing $50 \mu \mathrm{g} / \mathrm{ml}$ chloramphenicol to suppress bacterial growth. Plates were then incubated for 7 days at $28^{\circ} \mathrm{C}$ and examined visually for fungal growth. Five replicates were performed for each sample and the developing fungi were counted and identified according to the method of Raper and Fennell (1965), Moubasher (1993), Samson et al. (1995) and Pitt and Hocking (1997).

\section{Determination of FB1}

\section{Preparation of plant extracts}

A ground sample of each plant $(\mathrm{kg})$ with sodium chloride $(40 \mathrm{~g})$ was homogenized in a mixture of methanol/water $(80: 20 \mathrm{v} / \mathrm{v})$ for $5 \mathrm{~min}$ and the extract was then filtered through Whatman no. 4 filter paper. The filtrate was collected in a clean vessel, concentrated and taken for fumonisin B1 cleanup.

\section{Cleanup for Fumonisin B1}

The analytical method for the determination of FB1 in medicinal plant was carried out according to the method of Sewram et al. (2006). The filtered extract $(10 \mathrm{ml})$ was diluted with $40 \mathrm{ml}$ a solution of phosphate-buffer ( $\mathrm{pH} \mathrm{7.0)}$, the extract was then filtered and the filtrate was transferred into a polypropylene syringe barrel, which was attached to the FumoniTest immunoaffinity (IA) column (Vicam). The extract was passed through the IA column at a rate of about 1-2 drops/s until air passed through the column. Thereafter, $15 \mathrm{ml}$ of phosphate buffer was passed through the column at a rate of 1-2 drops/s. The fumonisin B1 was eluted from the IA column under gravity by passing HPLC grade methanol $(3 \mathrm{ml})$ through the column at a rate of $1 \mathrm{drop} / \mathrm{s}$ and the elute was collected into a glass vial, dried under a stream of nitrogen at $60^{\circ} \mathrm{C}$ and concentrated at the base of a small vial ( $4 \mathrm{ml}$ capacity).

\section{Derivatization and HPLC analysis}

Fifty (50) $\mu$ l of FB1 working standard solution was mixed with $225 \mu \mathrm{l}$ o-phthaldialdehyde (OPA) reagent $(40 \mathrm{mg}$ of OPA in $1 \mathrm{ml}$ methanol, diluted with $4 \mathrm{ml}$ of $0.1 \mathrm{M}$ disodium tetraborate and $50 \mu \mathrm{l}$ 2-mercaptoethanol) and $10 \mu \mathrm{l}$ of reaction mixture was injected to HPLC within $1 \mathrm{~min}$.

\section{Preparation of herbal tea extract derivatives}

The purified dry film residue of sample extract was dissolved in 200 $\mu \mathrm{l}$ methanol and $50 \mu \mathrm{l}$ of this extract was mixed with $225 \mu \mathrm{l}$ OPA reagent. About $10 \mu$ of the previous mixture was injected to HPLC within $1 \mathrm{~min}$ of adding OPA reagent.

\section{HPLC chromatography conditions and determination of FB1}

HPLC method was used for the determination of FB1 in positive samples according to the method of Shaphard et al. (1996). The HPLC instrument used for FB1 determination was waters delivery system 600 controller, equipped with fluorescence detector set system at $335 \mathrm{~nm}$ excitation and $440 \mathrm{~nm}$ emission wavelengths. The chromatography column was Nova-Pak C18 (150 x $3.9 \mathrm{~mm})$. The mobile phase system (water: methanol: acetonitriel, 6:3:1 v/v/v) was at flow rate of $1 \mathrm{ml} / \mathrm{min}$.

The derivative solutions of the standard or herbal tea extract were filtered through a $0.45 \mu \mathrm{m}$ membrane filter and $10 \mu \mathrm{l}$ was injected. The quantity of FB1 was determined from chromatographic peak areas using standard solutions containing 10-100 $\mu \mathrm{g} / \mathrm{ml}$ FB1 (Sigma F 1147). 
Table 1. $\%$ of humidity, total fungal counts, number of fungal and toxigenic isolates and quantity of FB1 $(\mu \mathrm{g} / \mathrm{kg})$ in herbal tea samples.

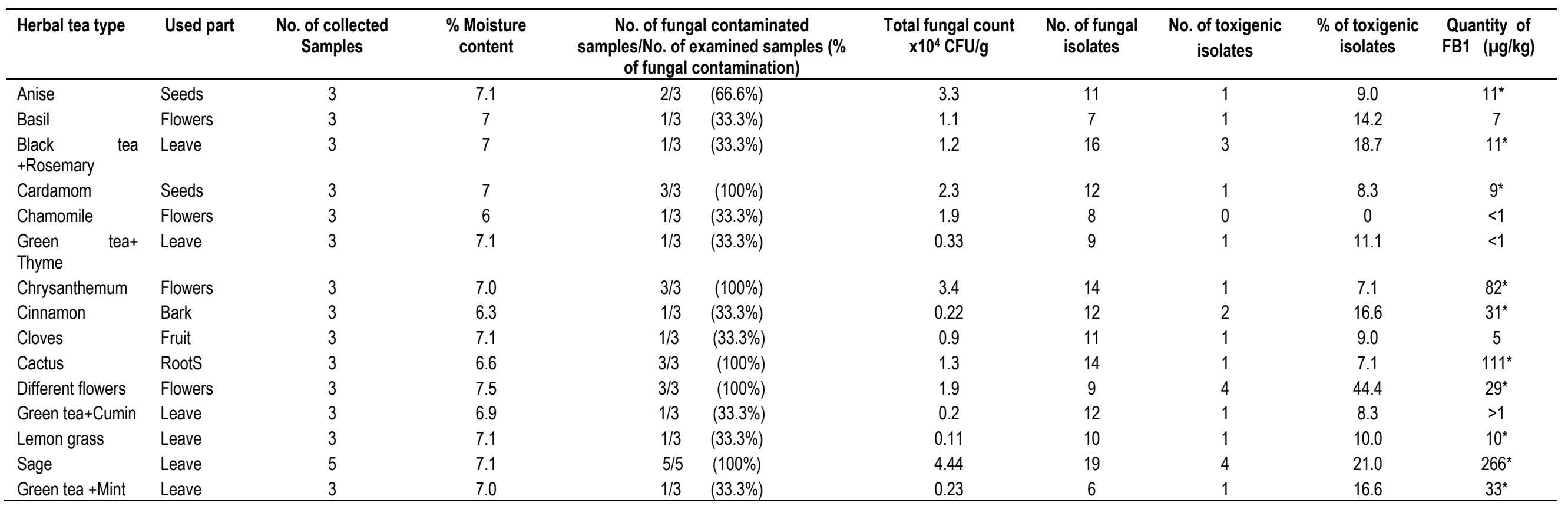

*: significant results at $p \leq 0.05$

\section{Statistical analysis}

Each experiment has three replicates and mean value was recorded. Student t- test was used to detect any significant differences between samples.

\section{RESULTS}

Various unpacked herbal teas including Anise, Basil, Rosemary, Cardamom, Chamomile, Thyme, Chrysanthemum, Cinnamon, Cloves, Cactus, Cumin, Lemon grass, Sage and Mint tea samples as well Black and Green tea were collected from different supermarkets and bazaars in Jeddah, Saudi Arabia. The most contaminated samples $(100 \%$ contamination) were Sage, different flowers, Chrysanthemum and Cardamom. The percentage of humidity, total fungal counts, \% of toxigenic fungi and quantity of FB1 for each sample were determined (Table 1). The percentages of humidity in the collected herbal tea samples were ranged from $6.3-7.5 \%$. The results of this investigation showed that fungal counts reached levels as high as $4.4 \times 10^{4} \mathrm{cfu} / \mathrm{g}$. Sage harbored the highest fungal contamination and the lowest counts of fungi were associated with Lemon grass $\left(0.11 \times 10^{4} \mathrm{cfu} / \mathrm{g}\right)$, Green tea with Cumin $\left(0.2 \times 10^{4} \mathrm{cfu} / \mathrm{g}\right)$, Cinnamon $\left(0.22 \times 10^{4}\right.$ $\mathrm{cfu} / \mathrm{g})$ and Green tea + Thyme $\left(0.33 \times 10^{4} \mathrm{cfu} / \mathrm{g}\right)$ The number of fungal isolates was as the follow: 16 fungal isolates were associated with Black tea +Rosemary, 14 fungal isolates were detected on
Cactus herbal tea and Chrysanthemum, 12 fungal isolates were detected on either Green tea + Cumin, Cardamom or Cinnamon. Green tea + Mint (6 isolates) and Basil (7 isolates). The highest number of toxigenic isolates was found on Sage and different flowers herbal tea (4 toxigenic isolates). The lowest number of toxigenic isolates on herbal tea were isolated from Green tea + Mint, Lemon grass, Green tea + Cumin, Cactus, Cloves, Chrysanthemum, Cardamom, Basil and Anise. Samples were analyzed for presence and level of fumonisin B1 (FB1). The quantity of FB1 was ranged from $0-266 \mu \mathrm{g} / \mathrm{kg}$ with mean value of $39.14 \mu \mathrm{g} / \mathrm{kg}$. The most contaminated herbal tea sample was sage $(266 \mu \mathrm{g} / \mathrm{kg})$ and the less contaminated was both Green tea + Cumin and 
Green tea+Thyme.

The most common fungi found (high occurrence) in herbal teas were Aspergillus niger, A. parasiticus, Fusarium sp. and Trichoderma (Table 2). Moreover, Alternaria alternate, A. humicola, Geotrichum sp, Penicillium citrinum and $P$. corylophylum were of moderate occurrence. However, A. ochraceus, A. fumigates, A. sydowi, A. terreus, Chaetomium sp., Cladosporium sp, Eurotium rubrum, Gliocladium sp, Paellomyces sp. and Penicillium sp. were of rare occurrence. The highest count was recorded for $A$. niger (16.4\%) of the total fungal count.

\section{DISCUSSION}

Herbal tea samples including Sage, different flowers, Chrysanthemum and Cardamom were highly contaminated with fungi (100\%) whereas samples contained Black tea, Green tea, Lemon grass, Cloves, Cinnamon and Chamomile were less contaminated (33.3\%). This may be attributed to the caffeine and/or antifungal content of these commodities. There is evidence that medicinal plants or herbal tea may be contaminated with toxigenic fungi including Aspergillus and Fusarium (Elshafie et al., 1999; Abou Donia, 2008). Certain plant constituents are susceptible to chemical transformation by contaminating microorganisms. Withering leads to enhanced enzymes activity, transforming some of the constituents to other metabolites not initially found in the herb. These newly formed constituent (s) along with the molds such as Penicillium nigricans and $P$. jensi may then have adverse effects (De Smet et al., 1992).

The percentages of humidity in the collected herbal tea samples ranged from 6.3-7.5\%. Hasan and Abdel-Sater (1993) recorded lower level of moisture content of the tea samples where it was fluctuated from $5.2-6.8 \%$. Increasing water content may enhance fungal contamination and mycotoxin production (Bokhari and Aly, 2009). Moreover, contamination of tea by mycoflora and mycotoxin is favored by high humidity and high water activity (Hasan and Abdel-Sater, 1993). Microbial counts are thus a reflection of the original bioload of microbes as well as of die off that are probably enhanced by oxidation and the presence of active compounds in herbs and spices (Farkas, 2000).

The collected herbal tea samples were contaminated with fungi $(33.3-100 \%)$ and the total fungal counts were up to $4.4 \times 104$. The differences in colony forming units $(\mathrm{cfu} / \mathrm{g})$ in different herbal tea were non-significant. Thus, all the tested herbal teas met all the hygienic conditions concerning them according to District Court Action No. 294/1997. Similar results were obtained by Rezacova and Kubatova (2005) who found the most contaminated sample of tea contained only $1.2 \times 10^{3} \mathrm{cfu} / \mathrm{g}$, which was lower than the cited notice Act no. 294/1997 $\left(<10^{5} \mathrm{cfu} / \mathrm{g}\right)$. Lutomski and Kedzia (1980) reported that $10 \%$ of the analyzed samples from 95 different crude herbal drugs contained $<10^{2} \mathrm{cfu} / \mathrm{g}$ molds, $38 \%$ contained $10^{2}-10^{3}$ cfu/g, 28\% had $103-104$ and $24 \%$ had $>10^{4} \mathrm{cfu} / \mathrm{g}$. Schilcher (1982) analyzed 548 samples of seeds and 221 samples of crude herbal materials (barks, flowers, leaves, fruits, herbs, roots and rhizomas) and found that the total count of aerobic bacteria in samples was $10^{2}-10^{7}$. Halt (1998) suggested that medicinal plant material and possibly herbal teas, if stored improperly allowing for mould growth should be analyzed for mould and mycotoxin prior to use.

In this study, the mycoflora of herbal tea was distributed in 13 genera comprising 25 species in majority of the tested herbal tea samples; $A$. niger was found and represented $16.4 \%$ of the total fungal counts. Many authors carried out mycological examination of teas and recorded the dominance of $A$. niger (Ostry et al., 2000; Ostry et al., 2002; Rezacova and Kukatova, 2005). Rezacova and Kukatova (2005) indicated no relationship between the particular microfungal species and a type of tea studied and high occurrence of $A$. niger in herbal tea samples could be due to low water content of tea which is preferred by $A$. niger. The most important toxigenic fungus $A$. flavus was found in only 9 out of 47 samples $(18.8 \%)$ and it represented $4.9 \%$ of total fungal counts. $A$. flavus is a known producer of aflatoxin and the percentage of occurrence calculated by Rezacova and Kukatova (2005) was $13 \%$, which was lower than the previous percentage. Elshafie et al. (1999) recorded $A$. niger as the most dominant species in all examined tea brands and the percentage of tea contamination with $A$. niger ranged between 0.66 and $30.34 \%$. Abdel-Hafez and El-Maghraby (1992) indicated that $A$. flavus, $A$. fumigatus and $A$. niger were the most prevalent in some drinks including tea and the total count of fungi was regularly increased with the rise of moisture content and storage periods. They added that out of 20 isolates of $A$. flavus, 15 isolates produced $\mathrm{B} 1, \mathrm{~B} 2, \mathrm{G} 1$ and $\mathrm{G} 2$, while five isolates produced $\mathrm{B} 1$ and $\mathrm{B} 2$ and $A$. flavus had the ability to produce aflatoxin in all kinds of tea after 20 days of incubation at $45 \%$ moisture content. Furthermore, the results of Bugno et al. (2006) indicated that the predominant mycoflora from 91 herbal plant was distributed in 10 fungal genera, $89.9 \%$ of the isolates corresponded to genera Aspergillus and Penicillium, which are extremely important from the mycotoxicological standpoint. Moreover, they added that $21.97 \%$ of the Aspergillus and Penicillium isolates proved to have the ability for producing aflatoxins $(42.9 \%)$, ochratoxin A $(22.4 \%)$ and citrinine (34.7\%). The mycofloral analysis of twenty different kinds of black tea powder (commonly used in Egypt) indicated that about 7 genera, 23 species and 2 varieties were recorded and the most prevalent mould were Aspergillus, Penicillum, Cladosporium and Eurotium (Hasam and Abdel-Sater, 1993). Moreover, Aspergillus, Penicillium, Mucor, Rhizopus, Absidia, Alternatia, Cladosporium and Trichoderma were the common genera isolated from 62 samples of medicinal plant 
Table 2. Distribution of the detected fungi in samples of herbal tea.

\begin{tabular}{|c|c|c|c|c|}
\hline $\begin{array}{l}\text { Fungal genera } \\
\text { and specie found }\end{array}$ & $\begin{array}{l}\text { Occurrence } \\
\text { remark }\end{array}$ & $\begin{array}{c}\text { Number of } \\
\text { Appearance/47 samples }\end{array}$ & $\begin{array}{c}\text { Mean value of } \\
\mathrm{cfu} / \mathrm{g} \times 10^{3}\end{array}$ & $\begin{array}{l}\text { Percentage of occurrence of } \\
\text { the total fungal count }\end{array}$ \\
\hline Alternaria alternata & $M$ & 13 & 2.5 & 4.9 \\
\hline Aspergillus ochraceus & $\mathrm{R}$ & 5 & 1.0 & 1.9 \\
\hline Aspergillus flavus & $\mathrm{H}$ & 9 & 2.5 & 4.9 \\
\hline Aspergillus fumigatus & $\mathrm{R}$ & 5 & 1.0 & 1.9 \\
\hline Aspergillus humicola & $M$ & 20 & 2.9 & 5.6 \\
\hline Aspergillus niger & $\mathrm{H}$ & 44 & 8.4 & 16.4 \\
\hline Aspergillus parasiticus & $\mathrm{H}$ & 23 & 1.0 & 1.9 \\
\hline Aspergillus sydowi & $\mathrm{R}$ & 5 & 1.8 & 3.5 \\
\hline Aspergillus terreus & $\mathrm{R}$ & 5 & 1.34 & 2.5 \\
\hline Chaetomium sp. & $\mathrm{R}$ & 5 & 1.81 & 3.5 \\
\hline Cladosporium $s p$ & $\mathrm{R}$ & 5 & 1.11 & 2.1 \\
\hline Eurotium rubrum & $\mathrm{R}$ & 4 & 2.34 & 4.5 \\
\hline Fusarium moniliforme & $\mathrm{R}$ & 4 & 1.34 & 2.5 \\
\hline Fusarium spp. & $\mathrm{H}$ & 34 & 2.30 & 4.5 \\
\hline Geotrichum sp & $M$ & 23 & 0.11 & 0.21 \\
\hline Gliocladium sp & $\mathrm{R}$ & 4 & 0.17 & 0.33 \\
\hline Mucor spp & M & 23 & 2.32 & 4.1 \\
\hline Paellomyces sp. & $\mathrm{R}$ & 5 & 0.99 & 1.9 \\
\hline Penicillium citrinum & $M$ & 15 & 2.30 & 4.5 \\
\hline Penicillium corylophylum & M & 24 & 1.41 & 2.7 \\
\hline Penicillium corylophylum & $M$ & 20 & 0.88 & 1.7 \\
\hline Penicillium sp. & $\mathrm{R}$ & 5 & 0.88 & 1.7 \\
\hline Phoma & $\mathrm{R}$ & 5 & 0.178 & 0.33 \\
\hline Rhizopus sp. & $\mathrm{R}$ & 4 & 1.94 & 3.8 \\
\hline Trichoderma sp. & $\mathrm{H}$ & 36 & 3.88 & 7.6 \\
\hline
\end{tabular}

$\mathrm{H}$, High occurrence (more than 25); M, moderate (less than 25 and more than 5); $\mathrm{R}$, rare ( equal or less than 5).

material and 11 herbal tea samples (Halt, 1998).

Fusarium sp. and F. moniliforme were found in 34 and 4 of the examined herbal tea samples, respectively representing $4.5 \%$ and $2.5 \%$ of the total fungal count. Fumonisin $\mathrm{B} 1$ is produced mainly by $F$. moniliforme that are prevalent in cereals and other agricultural products (Bezuidenhout et al., 1998). In Egypt, Aspergillus, Fusarium and Penicillium genera were more frequently detected than other genera (Alternaria, Absidia spp., Mucor spp., Rhizoctonia and Cladosporium spp.) in herbal samples (Abou Donia, 2008). Fusarium spp., Penicillium spp., $A$. flavus and $A$. niger were predominant in all tested herbal tea samples with the exception of garden sage samples (Martins et al., 2001a). In Sultanate of Oman, five fungal species were isolated from 48 samples of black tea with $A$. niger as the most dominant isolate followed by Aspergillus flavus, Penicillium spp. and Paecelomyces spp. (Elshafie et al., 1999). Rezacova and Kukatova (2005) did not find any effect of fermentation or origin of plant on the fungal species composition of black, green or herbal tea and most microfungi colonize the tea product later during processing. This hypothesis supports not only the fungal spectrum recorded (generally saprophytic fungi preferring dried food) but also the great difference in species composition between our results and fungal species isolated from soil of tea plants (Agnihothrudu, 1962; Farr et al., 1994). In Prague, Rezacova and Kubatova (2005) isolated 81 species of fungi from 40 samples of teas green, black and herbal teas but presence of Aspergillus species with known capacity for ochratoxin $A$ and aflatoxins production led the authors to issue warnings, which sparked more interest and investigation is required.

The results show that fungi that might constitute health hazards for humans might contaminate herbal tea post harvest and during processing which must be conducted under conditions that are more hygienic.

In this study, the detectable amount for FB1 in herbal tea ranged from $0-266 \mu \mathrm{g} / \mathrm{kg}$ using HPLC. No FB1 was detected on samples of Green tea + Cumin, Green tea + Thyme and Chamomile (Table 1). Contamination with Fumonisins generally caused acute toxic effects, pulmonary oedema (IARC, 1993) and esophageal cancer (Yang, 1980; Marasas et al., 1981, 1988; Sydenham et al., 1990). Other mycotoxin was detected by Abdel-Hafez and El-Maghraby (1992) who proved that tea powder was 
contaminated by aflatoxins $(26-81 \mu \mathrm{g} / \mathrm{kg})$. In Portugal, FB1 was detected in $55(65.5 \%)$ of the 87 samples (18 black tea samples and 69 herbal tea) for infusions preparations. The highest number of positive samples was found in black tea (88.8\%) with levels ranging from 80 to $280 \mu \mathrm{g} / \mathrm{kg}$ but chamomile had less contamination of FB1, with concentrations ranging from 20 to $70 \mu \mathrm{g} / \mathrm{kg}$, and none of the tested samples had contamination of FB2 (Martins et al., 2001b). Using HPLC with fluorescence detection, Omurtag and Yazıcıoglu (2004) detected FB1 in two samples $(0.160$ and $1.487 \mu \mathrm{g} / \mathrm{g})$ out of 115 commercially available herbal teas but FB2 was not detected in any sample.

In conclusion, fungi, which could conceivably constitute health hazards for humans, contaminate herbal tea and post-harvest contamination of tea can be reduced or even eliminated if tea processing is carried under the most hygienic conditions.

\section{REFERENCES}

Abdel-Hafez A, El-Maghraby OMO (1992). Fungal flora and aflatoxin associated with cocoa, roasted coffee and tea powders in Egypt. Cryptogamie Mycologie, 13:31-45.

Abou Donia MAA (2008). Microbiological quality and aflatoxigenesis of Egyptian spices and medicinal plants. Global Vet. 2:175 - 181.

Agnihothrudu V (1962). A comparison of some techniques for the isolation of fungi from tea soils. Mycopathol. Mycol. Appl. 16: 235242.

Atak G, Omurtag GZ (2003). 5th International Congress of Turkish Society of Toxicology, Antalya. p. 100, 176,

Aziz NH, Youssef TA, El-Fouly MZ, Moussa LA (1998). Contamination of some common medicinal plant samples and spices by fungi and their mycotoxins. Bot. Bull. Acad. Sin. 39: 279-285.

Aziz NH (1987). Etiology of toxin producing fungi from the class of deutromycetes occurring in various feed products. Ph. D. Thesis, Agricultural University, Cracow, Poland.

Bezuidenhout SC, Gelderblom WCA, Gorst-Allman CP, Horak RM, Marasas WFO, Spiteller G, Vleggar R (1998). Structure elucidation of the fumonisins, mycotoxins from Fusarium moniliforme. J. Chem. Soc. Chem. Commun., 11:743-745.

Bokhari F, Aly MM (2009). Trials towards reduction of fungal growth and Aflatoxin G1 production in Arabic coffee using different additives. Afr. J. Food Sci. 3 (3): 068-076.

Bugno A, Almodovar AAB, Pereira TC, Pinto T, Sabino M (2006) Occurrence of toxigenic fungi in herbal drugs. Braz. J. Microbiol. 37(1) $37: 47-51$

Chu FS, Li GY (1994) Simultaneous occurrence of fumonisin B1 and other mycotoxins in moldy corn collected from the People's Republic of China in regions with high incidences of esophageal cancer. Appl. Environ. Microbiol. 60:847-852.

De Smet PAGM, Keller K, Hansel R, Chandler RF (1992). Adverse Effects of Herbal Drugs, Vol. 1. Springer-Verlag, Heidelberg.

Elshafie AE, Al-Lawatia T, Al-Bahry S (1999). Fungi associated with black tea and tea quality in the Sultanate of Oman. Mycopathologia 145(2):89-93.

Farr DF, Bills GF, Chamuris GP, Rossman AY (1994). Fungi on Plants and Plant Products in the United States. p. 1252. St. Paul.

Gelineau-van Waes JB, Starr L, Maddox JR, Aleman F, Voss KA, Wilberding J, Riley RT (2005). Maternal fumonisin exposure and risk for neural tube defects: mechanisms in an in vivo mouse model. Birth Defects Res. Part A Clin. Mol .Teratol. 73: 487-497.

Halt M (1998). Moulds and mycotoxins in herb tea and medicinal plants. Eur. J. Epidemiol. 14(3): 269-274.
Hasan HAH, Abdel-Sater MA (1993). Studies on mycoflora and aflatoxin in regular and decaffeinated black tea. J. Islamic Acad. Sci. 6(2):124-130.

IARC (1993) IARC Monographs on the Evaluation of the Carcinogenic Risk of Chemicals to Humans, Vol. 56, Some Naturally Occurring Substances: Food Items and Constituents, Heterocyclic Aromatic Amines and Mycotoxins. IARC, Lyon.

Marasas WFO, Wehner FC, van Rensburg SJ, Van Schalkwyk DJ (1981). Mycoflora of corn produced in human esophageal cancer areas in Transkei, Southern Africa. Phytopathology 71:792-796.

Marasas WFO, Jaskiewicz K, Venter FS, van Schalkwyk DJ (1988). Fusarium moniliforme contamination of maize in oesophageal cancer areas in Transkei. Afr. Med. J. 74: 110-114.

Martins HM, Martins ML, Dias MI, Bernardo F (2001a) Evaluation of microbiological quality of medicinal plants used in natural infusions. Int. J. Food Microbiol. 15; 68(1-2):149-53.

Martins ML, Martins HM, Bernardo F (2001b). Fumonisins B1 and B2 in black tea and medicinal plants. J. Food Prot. 64(8):1268-1270.

Missmer SA, Suarez L, Felkner M, Wang E, Merrill Jr AH, Rothman KJ, Hendricks KA (2006). Exposure to fumonisins and the occurrence of neural tube defects along the Texas-Mexico border. Environ. Health Perspect. 114, 237-241.

Moubasher AH (1993). Soil fungi in Qatar and other Arab countries. The center for scientific and Applied Research, University of Qatar. $p$ 670.

Omurtag GZ, Yazıcıoglu D, Beyoglu D, Tozan A, Atak G (2005). A Review on Fumonisin and Trichothecene Mycotoxins. Bulletin of the Istanbul Technical University, 54(4):39-45.

Omurtag GZ, Yazıcıoglu D (2004). Determination of fumonisins B1 and B2 in herbal tea and medicinal plants in Turkey by high-performance liquid chromatography. J. Food Prot. 67(8):1782-1786.

Pitt JI, Hocking AD (1997). Fungi and Food Spoilage. Second edition. London: Black Academic and Professional Chapman \& Hall, 593p.

Raper KB, Fennell PI (1965). The genus Aspergillus. Williama and Wlkins, Baltimore, USA, 33-111.

Rezacova V, Kubatova A (2005). Saprobic microfungi in tea based on Camellia sinensis and on other dried herbs. Czech Mycol. 57(1-2): 79-89.

Samson RA, Hoekstra ES, Frisvad C, Fittenborg C (1995). Introduction to Food Borne Fungi. Fourth edition, Central bureau Voor Schimmelculture Baarn, The Netherlands. Wageningen, Ponsen and Looyen. 33-112.

Sewram V, Shephard GS, Merwe L, Jacobs TV (2006). Mycotoxin contamination of dietary and medicinal wild plants in the Eastern Cape Province of South Africa. J. Agric. Food Chem., 54(15): 56885693.

Shephard GS, Thiel PG, Stockenstrom S, Sydenham EW (1996). Worldwide survey of fumonisin contamination of corn and corn-based products. J. A.O.A.C. Int. 79: 671-687.

Tutelyan V (2004). Deoxynivalenol in cereals in Russia. Toxicol. Lett. 153: 173-179.

WHO (2000). Fumonisin B1, IPCS, Geneva

Yang CS (1980) Research on esophageal cancer in China: a review. Cancer Res., 40: 2633-2644.

Yoshizawa T, Yamashita A, Luo Y (1994). Fumonisin occurrence in corn from high and low risk areas for human esophageal cancer in China. Appl. Environ. Microbiol. 60 (5): 1626-1629. 